\title{
The Promise of Microprint
}

\author{
A Symposium Based on The Scholar and \\ the Future of the Research Library
}

\section{Appraisal: Keyes D. Metcalf}

W HETHER OR NOT micro-cards ever come into use in the form proposed, Fremont Rider's The Scholar and the Future of the Research Library may well prove to be one of the most important books dealing with libraries in this generation. This volume should be made required reading for library school students, and librarians of all ranks who do not read it carefully and try to think through the problems it discusses will deprive themselves of stimulation that they can ill afford to be without. It is probably the most dramatic book in library professional literature and is so full of meat that a review article the length of this one could profitably be written on any one of its seventeen provocative chapters. This statement cannot attempt to cover more than a small percentage of the points that are worthy of comment, and those chosen are the ones where criticism rather than praise seems justified. It would have been easier and pleasanter for the reviewer to use all his space for a discussion of subjects where he had nothing but commendation to offer. He feels, however, that the points which he has selected are vital and should be aired.

Mention should be made at this point of Mr. Rider's earlier articles, which are listed in a note in the preface of his book and which deal with library costs, cataloging, cooperation, and growth. They also should become required library school reading. No other writings in this field are more thought provoking or deal with more basic library questions.

The first chapter, that on the "Growth of American Research Libraries," is of special interest to this reviewer. Here is a problem that affects, and in many ways forms the basis for, other serious library problems, and yet it is one that has never, up to this time, been presented more than superficially except in Mr. Rider's papers. Librarians have refused to face the facts of growth. They have optimistically believed that the geometric progression of the past would not continue. Mr. Rider, through the articles just mentioned and now in the first chapter of this book, has converted many librarians to the thesis that since libraries have been doubling every sixteen years for the past three centuries, there is reason to believe they will continue to do so. The reviewer takes the stand, however, that the turn of the road was reached even before the great depression of the I930's; that the second World War has made the turn an abnormally sharp one; and that the future growth of our larger libraries, taken as a group, will be more by arithmetical progression than by geometrical. If $\mathrm{Mr}$. Rider had checked the reports of the New York Public Library and of the Harvard and Yale college libraries, the only large libraries in the United States that could be considered to have reached even adolescence, to say nothing of maturity, thirty-two years ago (the Library of Congress, while over a hundred years old, was then still in its infancy as a great national library), he would have found that they have failed to quadruple since that time and that their rate of growth on the percentage basis has been steadily decreasing. If he had checked the "Gerould statistics" for the libraries that had passed the five hundred thousand-volume mark sixteen years ago, he might have modified his figures, because he would have seen that, as libraries of any type grow larger, they tend to grow less rapidly. If he had considered the great libraries of England and France, which are old enough to form a sound basis for study, as American libraries are not, or if he had studied the United States Census 
reports from $I 790$ to date, it might have put a different face on his fears.

In connection with the growth question, it seems proper to suggest that it is only when a library reaches the five hundred thousandvolume mark that the problem of storage space for books necessarily becomes of first importance. This is said with no desire to minimize the complications now facing many of the smaller libraries. If it is realized that in I94I a book stack with shelving adequate for $1,100,000$ average-sized books could be built for $\$ 175,000$ - this at a time when a New England college library with half a million volumes, which could have been housed on the above basis for less than $\$ 100,000$, occupied a building costing well over $\$ 1,000,000-i t$ will be seen that the cost of book storage in a middle-sized library is not as large a factor as some other space problems. It is only fair to remind the reader at this point that Mr. Rider very wisely emphasizes the fact that the cost of book storage is but one of the four expenses he discusses that result from growth.

If the reviewer is correct in his belief that libraries will not continue to grow geometrically as in the past and if cooperative warehouses and the other economies which $\mathrm{Mr}$. Rider discusses with great perspicacity (but all too briefly and with, perhaps, too little emphasis) are used, the situation is not so desperate that precipitate action is indicated. Certainly the cautious librarian will hesitate to jump out of his present frying pan of possible geometrical growth until he knows more about the temperature in the proposed microcard library.

Mr. Rider, as a frontispiece to his volume, shows a hundred pages on the back of a standard-size catalog card. $\mathrm{He}$ states that this, being a reproduction of a reproduction, is not readable, but gives the impression in chapter 2 of the second part of his book that printing by the Boni method makes legible results possible. They certainly are possible by straight photographic reproduction on smooth sensitized paper, but as the limit of reduction, up to the present, by the Boni method of offset printing is ten or twelve diameters, and the micro-card plan calls for a greater reduction, it seems doubtful if the technical problems are as yet solved even to the extent of printing a hundred pages on the back of a card, to say nothing of two hundred and fifty or more. This conclusion is reached because the Readex microprint project has run into many difficulties when it has attempted to put two or three pages on one square inch of space instead of the seven pages used on the sample in the volume, to say nothing of the eighteen that the author indicates he is looking forward to. $\mathrm{Has} \mathrm{Mr}$. Rider given sufficient weight to the efforts of $\mathrm{Mr}$. Boni to solve the simpler problem satisfactorily? The desirability of greatly reduced printing on paper was presented to the Eastman company before microfilm came into use in libraries. The technical problems involved were studied by that company and, according to the best authorities, they are not yet completely solved. Until they are solved or are much further on their way to solution than they now seem to be, libraries cannot be expected to make the investment that will be necessary to put Mr. Rider's plan into action. This does not mean that the time is not ripe for consideration of the micro-card proposal; if we can decide now where we want to go, and prepare minimum standards, we shall be ready to make the most of technical advances as soon as we get them.

\section{Administration and Costs}

Leaving technical problems out of consideration, has $\mathrm{Mr}$. Rider given adequate weight to the administrative problems and the costs involved in his plan when he suggests five cents apiece as the selling price of microcards? He very properly omits copyrighted books because of legal complications. His case for other American books for which $\mathrm{Li}$ brary of Congress cards are available, and for which the cataloging savings would thus be reduced, is not strong enough to make them the most satisfactory point of departure for his project. One natural place to begin seems to be with noncopyright books that are not represented in the Library of Congress catalog. But how can a library that is prepared to take its share of the burden of the new plan acquire the necessary three copies of this type of book before it begins work? If they are acquired, what are the handling charges going to be? Publishers have always found, much to their regret and to that of librarians, that the smaller the production cost of their wares, the larger the percentage 
of overhead. Will micro-card publishing librarians not find that the overhead proves to be very much larger than anticipated, since so much of the work will have to be done by hand instead of by the automatic cameras now used to copy catalog cards onto microfilm?

A few comments should be made on the chapters dealing with cataloging problems, more to indicate debatable points than to argue against the author's basic theory and incidentally to show the many-sided interests of this remarkable book. Subject cards are praised and their multiplication highly recommended. The reviewer has never been as enthusiastic a supporter of subject cards for research material as many of his colleagues have been, although he is aware that they have come to stay and have their uses. The assignment of subject headings has always seemed to him far from being an exact science, and he is troubled by their tendency to become unsatisfactory as they grow older and the catalog becomes larger and more complex. They are expensive to assign, and there is considerable question as to the extent of their value in a research library. The reviewer has found more and more evidence at the New York Public Library and at Harvard that it is the undergraduate student or the novice who makes the greatest use of the subject catalog, while graduate students and advanced research workers are inclined to ignore it, at least when it comes to the types of books for which Mr. Rider advocates micro-cards.

\section{Growth of Catalogs}

It also seems not improper to mention the deep impression made by Mr. Rider's earlier articles on the tendency of card catalogs to fall by their own weight and to become larger and more complicated as the years go by. One is tempted to state that this project, particularly the subject-card part of it, seems to be piling Pelion on Ossa as far as complications in the catalog are concerned. At this point it seems worth while to comment again on Mr. Rider's theory of growth in libraries and catalogs. He tells us at the top of page I2 that the Yale library in the year 2040, if the present rate of growth continues, will have approximately 200,000,000 volumes, which will occupy over six thousand miles of shelving. He goes on to say that this will require a card catalog of nearly three-quarters of a million drawers, which will occupy not less than eight acres of floor space. New material, he says, will be coming in at the rate of twelve million volumes a year, and the cataloging of this new material will require a cataloging staff of over six thousand persons. Mr. Rider believes that if his proposal goes into effect, the Yale library in 2040, instead of having two hundred million volumes, will have a very much smaller number of volumes of the present type and a microcard library of much greater numbers. At present, Yale has less than one-tenth of the books now in existence, and it will want to have a complete author, title, and subject record of all books. Mr. Rider suggested that its micro-card catalog will add analytical cards of various kinds, including author and subject entries for most periodical articles and parts of many books, and so, instead of being ten times the size of the card catalog that would have prevailed under the old order, it might easily be forty times as large. It would then have thirty million drawers of cards which would occupy three hundred and twenty acres of floor space, or just half a square mile. If they are all stored on one level, the catalog would occupy a building some fifteen times the size of the Harvard Yard (unfortunately the Harvard library appears not to have a record of the size of the Yale campus), and Yale, instead of having a cataloging staff of over six thousand persons, would have a filing staff of somewhat similar size. This would certainly be cheaper, but it does not demonstrate that micro-cards would settle the problem of library growth for even one century.

One more point that cannot be ignored and that rightly or wrongly is of importance. Mr. Rider emphasizes the fact that librarians should provide their research workers with the materials that they want, and he thinks that a special collection in California does not satisfy the scholar in New York. All too true, but unfortunately it has become apparent to many librarians that micro-reproductions do not satisfy the research worker and that many, or perhaps most of them, prefer to wait for an opportunity to go to California to see the originals, or at least wait until the desired volumes can be brought 
to New York by interlibrary loan, rather than to read them in micro-reproductions of any kind. That may be an unreasonable attitude, and it is to be hoped that time and improved apparatus will alter it, but it is well to remember that there are some things that a photographic reproduction fails to tell the scholar which he can learn from the original. While it is not particularly pertinent to this review, the opportunity is taken to suggest that the library and bibliographical world is still waiting for a definitive statement of what micro-reproduction cannot do. Naturally, with a new tool emphasis has been given to what it can do, and indeed in some ways the over-enthusiastic promoters of microphotography may have been its worst enemies by convincing the uninformed that it will solve all library problems.

\section{A Look Ahead}

The editor has suggested that this article try to look ahead. The reviewer is no prophet, and has no desire to be one, but he agrees with Mr. Rider that libraries with books in their present form will go on, microcards or no micro-cards. Microphotography has undoubtedly found its place for newspapers and interlibrary loans. It will be used in some form to reproduce rare books that cannot be acquired in any other way. It is a matter of tremendous importance, whether we like it or not, but it is not the only answer to space and financial problems of libraries. The librarians of even the largest institutions are gradually realizing that no one library can own copies of all printed materials either in the original or in photographic reproduction. This means that there is need for more emphasis on bibliographical tools and apparatus, so that references can be found to what a library does not possess and arrangements can be made to borrow it in some form, or perhaps later on to use it with the aid of television. The large libraries should continue to do what they can to acquire good working and reference collections in all fields which they expect to cover, but when it comes to research collections, there should be a division of fields. There should be, as far as possible, at least one copy of every printed work conceivably of interest to the research worker somewhere in this country, and it should be comparatively easy for the scholar to find that copy and in many cases to borrow it or acquire a reproduction of it.

The reviewer would like to go on another step and be recorded as approving of micro-reproduction in some form and in ever-increasing quantities. He thinks those reproductions should be in sheets (flat form) rather than in rolls, as that shape is better adapted to research workers and library convenience and practice. $\mathrm{He}$ believes that the advantage of offset printing over photographic printing in the case of any but the smallest editions, and of paper over film, are so great that microprints will be the winner in the race in spite of the disinclination of the great photographic supply manufacturers to push them and in spite of the technical problems involved, which will always make possible larger reductions with film than with paper. $\mathrm{He}$ is not yet ready to cast his vote for either $\mathrm{Mr}$. Boni's readex plan or Mr. Rider's micro-cards but he believes that, whichever or whatever form is decided upon, the material selected for reproduction should be, in most cases, a collection of one kind or another and as complete as possible a representation of titles in some standard bibliography or index, so that the cataloging and recording problem will be reduced to a minimum. As an example of this principle, Mr. Power's microfilm project of British books published before 1550 may be noted or Professor Erickson's British Sessional Papers.

If the reviewer seems to be very critical, he wants to reiterate his conviction that $\mathrm{Mr}$. Rider's book is an important one. It is important because of its exposition and summing up of problems that come from the tendency of libraries to grow geometrically and absorb a larger and larger sum of money to keep them going. It is important because of its stimulation and its new point of view and because for the first time it puts down in black and white a proposal that sooner or later in some form or other will bring another advance in man's methods of communicating knowledge. Speech, drawing, the alphabet, the invention of paper, the form of the book, printing, the composing machine, and photography, are some of the more noteworthy steps. Microprints and micro-cards fall in the last of these, or more accurately 
in the combination of the last three, and ultimately may be one of the more important phases of these steps.

It would have been possible and pleasanter for the reviewer to have used his space in commenting on the many parts of the book where he agrees heartily with the author, and he has failed to do so simply because he felt the necessity of urging caution on the points that have been discussed. The book is so well done that many of its readers will naturally be carried away by enthusiasm for it.

There is great danger of our civilization falling under its own weight. Libraries and librarians have at least part of the responsibility in keeping as simple as possible the records of that civilization, so as to postpone its fall. Mr. Rider's book is a brave attempt to help. It is certainly a landmark in the struggle, because of the way it puts very clearly before us many of the more difficult library problems. It proposes one way out. In the reviewer's opinion, however, it goes too far and too fast, even if it is in the right general direction. It should not and cannot be ignored. It is strongly recommended that you read Mr. Rider's book and read every word of it with care.-Keyes D. Metcalf, director of libraries, Harvard University.

\section{Brief Comments: Eight Librarians}

Fremont Rider has given yeoman service to the library profession in preparing The Scholar and the Future of the Research Library, because of the dramatic attention he has focused upon the four great problems of research libraries: (a) The cost of original acquisitions and publications of scholarly and research publications are based upon methods and techniques that are primarily designed for much more extensive dissemination of the original than is usually required, hence the prices of original publications are almost certainly higher than their use and distribution warrant. (b) The growing physical bulk of research libraries is of such proportions that a positive way of limiting it must eventually be found. (c) The growing complexity in the organization and the tools of large libraries is such as to make library use increasingly difficult, even by patrons well informed on library procedures. (d) The preparation costs, including classification, cataloging, and related steps, are requiring a constantly increasing proportion of available library funds.

Mr. Rider discusses either directly or by implication all of these problems, and his argument is convincing that half measures in connection with them will not suffice. $\mathrm{He}$ makes it clear that major and radical steps must be taken toward finding a solution. The micro-card system, which he has outlined in considerable detail as offering a potential answer to part or all of the problems, merits serious consideration, despite Mr. Rider's tendency to minimize some of the technical problems.

Whether the micro-card proposal as it is now outlined in Mr. Rider's book is feasible or not is at this time a question of no very great importance. Mr. Rider's contribution is that of making a serious suggestion unfettered by tradition or precedent and of such a nature as to attack several of the major troubles of research libraries simultaneously. It is reasonably obvious that new and alternative proposals along these lines, together with the resulting defenses of present procedures, can only be of benefit to libraries in promoting a solution.

One should carefully note the limitations that are implicit or disclosed in the microcard program, for it is not a cure-all. The conception of photographic reproductions on flat surfaces is not novel. There are obvious benefits in reproducing certain types of material in this way, when satisfactory technical procedures can be evolved. There are also many objections, especially for certain kinds of originals. Nor, as Mr. Rider makes clear, is the reproductive technique or form alone sufficient to meet our situation. Much more is required, but $\mathrm{Mr}$. Rider has gone a long way in presenting the problems and an approach toward their solution that may well affect the "future of the research library," not to mention the scholar.-Herman Fussler, librarian, Metallurgical Library, University of Chicago. 
Mr. Rider has thought out a solution to a set of problems which have long confronted librarians. A careful reading of his book will show, too, that he has answered most of the objections that might be brought against his proposal. Speaking only from the technical point of view, I would say the microcard has great possibilities as a blessing to librarians and scholars. I would like to see it taken seriously enough to have it tried.

There is, however, going to be one obstacle to the adoption of micro-cards which must be faced. There is, as every librarian who works with microfilm knows, a psychological barrier between the scholar and the reading machine. It is not only the form which microfilm has taken that has prevented its full usefulness in libraries. There is still great reluctance on the part of librarians and readers even to consider the merits of microfilm. It is not facing facts to say, as Mr. Rider does, "There is no particular point in suggesting that one is afraid that the patrons of one's library wouldn't like microtexts of government documents." (p. 223) There is a point. The existence of such a feeling should be recognized and steps taken to combat it. Microfilm in any form it may take is even more in need of propaganda than of technical improvements.

The technical problems moreover are being worked on and, however improbable of solution they may seem, one hesitates to say they will not be solved. I would, therefore, not say that any number of pages, five hundred or more, may not one day be put on a three by five card. But if we are going to have reading machines as $\mathrm{Mr}$. Rider says "everywhere," they will have to be simple and inexpensive. In that case there will have to be a definite area magnified by them at one time. The space occupied by a page will have to be fixed.

We cannot ask a manufacturer to design a single reading machine which will enable us to read from one to five hundred pages of print on a three by five space. We will have to decide how many we want as a maximum. If we decide on five hundred, a twenty-page pamphlet would occupy the space that would be taken up by the first twenty pages of a five-hundred-page volume. Then if we also want to put single maps and pictures on micro-cards, we can say that too and have a second reading machine just for that. It is all very well to say that a large university will have hundreds of reading machines of various types. But a scholar will not be likely to be easily persuaded to have more than one, or at most two. Therefore, I believe there will necessarily be some standardization.

There is, of course, one way to settle all the questions raised by Mr. Rider's book. If the general principles of his proposal are sound, let us set up a library micro-card committee and work out enough of the details to make a start. If micro-cards are the solution to the problem, why not try them now?-Mary Angela Bennett, supervisor, Binding and Photography Departments, Columbia University Libraries.

Mr. Rider has not risked his prophet's license. Microprint will play a big role in library holdings. There seemed to many of us a real but undecipherable potential in the microprinting of the British Sessional Papers and the Church Catalogue. Mr. Rider projects probably the full usefulness of microprint, certainly he sets forth most of the best uses. These are as correctly magnified for librarians by his book as a micro-card is magnified for a scholar by its reading machine. In it he describes, as a skilled counsel for the defense would plead, the benefits of microcard publication with imagination, rhetoric, and terminology of great clarity, aimed at trustees, university administrators, and library committees, as well as at librarians.

But so persuasive a book is bound to have overenthusiastic disciples, due to no fault of Mr. Rider. He himself urges microprint mainly for rarely-used books and periodicals, theses, manuscripts, maps, ephemera, etc., and for the large research library. He could have added (but does not) sheet music as a custodial and service problem which microprint may solve and could have stressed the cramped special libraries in New York which it will serve as a space-saver as helpfully as any large libraries. But the layman with Mr. Rider's book may well misunderstand his delimitations and draw implications unwarranted by the present state of microprint art. There are problems of microprint technology, in production and in service, not yet worked out. This is no reason for not experimenting at 
once on a pilot plant basis and Mr. Rider so advocates. There are reasons, however, for being cautious, maintaining the rate of growth of our collection, buying a scholarly set if we can. We had, also, better not surrender any space. Trustees should not stop a library building program on microprint's account. Most buildings are inadequate now in reader space, and microprint may require greater and less flexible use of floor space for its service.

The tone of vigorous argument in $\mathrm{Mr}$. Rider's book may well egg the layman on, into pushing microprint too fast for its own final best use, by giving the impression that librarians unreasonably resist technologic change. To the contrary, the adoption of technologic change to meet recurrent crises caused by rapid growth is an old story in our library history. Card catalogs which allowed constant intercalating were accepted because they gave a control over rapidly growing collections which the formerly used book catalog did not. Rapid growth, with demand for reader access and the possibility of classified arrangement of books, also caused installation of flexible shelving, another technologic change. Microprint will not affect library methods as universally as these, which are in effect in the smallest libraries. We owe Mr. Rider the justice of not considering his proposals unduly revolutionary. For most of us the receipt of microprint publications on cards will be much like the present receipt of Engineering Index entries on cards. The micro-card will bring changes, but those comparable in the library of a university to that caused by a new department, e.g., a geography department with a library increase in map holdings. Most scholarly libraries have withstood more than one such expansion. For the score or so libraries which Mr. Rider would have publish micro-cards, the effect will not greatly differ from adding photo- or phonoduplication laboratories, which they have already survived.

We thank Mr. Rider, Mr. Boni, and the microprint pioneers for help with print. Now, who has an idea on storage and service for pictures, moving and still, and for sound recordings?-John H. Moriarty, director of libraries, Purdue University.

I have just finished reading $\mathrm{Mr}$. Fremont Rider's most intriguing book, The Scholar and the Future of the Research Library. His ideas are most provocative and would seem to be most important. But it is apparent that $\mathrm{Mr}$. Rider is ridden with a disastrous fear-the fear of expense. It seems to haunt his book and is summed up in his statement that not only the purchase price but also the cataloging, binding, and storage costs of research material must be not just cheap but "amazingly cheap."

This fear of expense, this passion for cheapness, seems to me to weaken his whole idea on three counts. In the first place, he insists that subject headings must be standardized and be printed on the micro-cards by the issuing library-to make the cataloging cheaper. In the second place, he states that modern copyrighted books will not be microcarded because it will not be possible to pay the publisher of the book enough to get permission for such reproduction. Finally, he wants what he calls "global" sales of microcards and would make it impossible for libraries to buy cards for single books in fields other than those for which they subscribe-again because it would cost more money to sell them in this way.

Yet Mr. Rider also complains that librarians are not sufficiently forward-looking and enterprising. He writes that "the largest union cataloging project ever attempted, the largest bibliographical project ever carried on, the largest printed catalog ever completed, the most searching criticism of cataloging methods of recent years, were each and every one of them directed not by a professionally trained cataloger but by someone drawn from an alien field." I cannot escape the feeling that there is a contradiction here. Three of the four items that $\mathrm{Mr}$. Rider lists are projects that must have cost a great deal of money-yet Mr. Rider insists that his own project must be carried through and result in "amazing cheapness." Can we have both? Can we have big, expansive ideas and a penny-pinching attitude at one and the same time? Or is the fear of spending one cause of the librarian's failure to promote the more important library projects?

Is not this demand for cheapness the result of an ultraconservative outlook on $\mathrm{Mr}$. Rider's part? That I am not jumping at conclusions would seem to be evidenced by the approval which he expresses in his book of 
what he terms the librarian's natural, and proper, conservatism. At a time when great plans are being laid for a better and more expansive life after this war, Mr. Rider demands that what would be a revolution in the library world be carried out cheaply. Why? Have librarians lost their belief in the importance of the role the library plays in modern life?-and are they unable or unwilling to fight for the money necessary to enable it to play that role?

I am perhaps unfair to Mr. Rider in thus singling him out, for "cutting costs" seems to have become the main theme of library literature in the last few years. Are our cataloging costs really "swollen" or are librarians afraid to stand up and fight for the money necessary to make their catalogs what they should be-the finest bibliographical tool in their library? It is just because Mr. Rider's project is so full of possibilities that I would raise my voice against an attitude that might weaken or even wreck it. Why shouldn't publishers be paid a sufficient amount to make it worth their while to grant libraries the right to reproduce books on micro-cards? And why shouldn't the library have enough help to subject-head its own cards? We can and should have an economy of abundance after this war, and librarians should be leading the way, should be insisting that the full possibilities inherent in our modern civilization be developed.

Perhaps what our librarians need most is to get away from their professional tasks long enough to read some of the books in their own libraries, books on this changing world. They would do well to note that not one but both major parties in the election campaign just concluded called for faith in this country's future, for expansion, for jobs for all. Many of us believe that this can be our future and I for one should hate to see the library profession standing with its back toward the future crying aloud in the wilderness that "it must be cheap."

Perhaps we need a library manifesto to free us from our conservative chains, to rally us with the cry, "Librarians of the World, Grow!" The world must be a bigger and better place and librarians must take a bigger and better place in it. Until we look at this changing world with our eyes open, and approach our profession like men, not mice, we shall remain a professional group working for a clerk's salary, a group that stagnates while the world expands. If we can open our eyes, if we can have the faith and courage to call for the funds necessary to carry on our profession properly, then we may see ideas like Mr. Rider's reach their full development, and librarians, not outsiders, leading great library projects.-John B. Montignani, assistant librarian, Metropolitan Museum of Art, New York City.

Mr. Rider's book gives to the library profession a masterly statement of the principal long-range problem, namely growth, confronting research libraries. It gives, too, an admirably conceived, lucid presentation of his solution, which lies, as we all know, in the use of the micro-card. Since we have learned something of the astonishingly large amount of printing or writing that can be reproduced through this medium, it is difficult, to put it mildly, in the absence of some still more efficient space-saving device, not to embrace micro-cards as the panacea for libraries' "growing pains." Furthermore, since Mr. Rider succeeds nobly in answering what appear to be the major questions and objections to his proposal, it does seem that he is entirely justified in calling for trial action (doubtless he would take issue with the use of the word "trial") along the lines he has laid out. In this connection it is to be hoped that if his plan for micro-card publishing offers the best method for manufacture and distribution, the acknowledged difficulties facing any divisionof-fields scheme can be overcome and adequate, satisfactory cooperation among sponsoring libraries thereby affected.

While probably not of outstanding importance, it would be interesting to be able to determine with some accuracy the rate at which the size of our present libraries would tend, after introduction of micro-cards, to become stabilized or "fixed." In attempting to determine the effect of the cards on future library economy, we might ask, When will the rate at which material is published on microcards permit a library to withdraw (and, incidentally, this process involves a cost to be accounted for) enough books from its shelves to balance the amount of material which is newly published in conventional book form and must be added? It would be helpful 
indeed to be able to tell whether this date would come soon enough to save us from being engulfed by the overwhelming output of new materials.

Micrb-cards and the proposed extensive analytical cataloging and abstracting of the books they contain would render great service to the reader by bringing an increasing amount of material together wand by predigesting at least some of it for him. Obviously microcards would render tremendous service too in enabling him to develop in a location convenient for him a collection of many standard reference tools and important source materials, if available on micro-cards. And as time went on more and more of this material, including theses, documents, maps, manuscripts, and newspapers, would be available in this form, a development of inestimable value to research. However, for material not on micro-cards the reader, of course, would still have to turn to the separate conventional card catalog, to the collection in book form, and to other sources.

The probable rapid growth of the microcard catalog might bring problems for the librarian and for the reader. Would not its increasing size require more and more staff, all the while retaining the present circulation staff for the conventional book collection, to assist in its maintenance and use, and to refile an enormous number of cards withdrawn, many perhaps for a short time only for browsing in the room or rooms in which the catalog is housed? Would not such browsing-taking out cards (some perhaps without charges?) for the purpose of examining them on a reading machine to see if they are useful-result in congestion and confusion? These conditions might easily make trouble, either because there was an excessively large number of charges to be handled or because a momentary withdrawal of a card without a charge, by one reader, prevented the finding of it by another.

Then, too, is there not likely to be considerable labor needed for replacing cards which through constant handling become too dirty and worn for further service and also others which have disappeared? It does seem that micro-cards, because of their size and shape, would tend to get lost. But the few foregoing comments and questions, insofar as they pose service difficulties, are admittedly of relatively minor importance. And even if micro-cards were of doubtful value on ninetynine out of every hundred counts, they would still argue eloquently for the recognition due them as a means for preserving and making available, in a form easier to use than microfilm, the considerable material published today on paper too poor to last.-Edward G. Freehafer, assistant librarian, Brown University.

The impact of Mr. Rider's study is certain to be felt on many aspects of librarianship but perhaps on none more forcefully than the field of library cooperation and the development of resources for research.

For the past thirty or forty years farseeing librarians have recognized the evils of competition and the wastefulness of excessive duplication among university and other research libraries. Innumerable books, articles, and conferences have centered on the desirability of greater specialization among libraries, limitations of fields, regional agreements, and building up of union catalogs. In view of the shining goals to be achieved, practical progress in these directions has seemed to many of us distressingly slow. Now comes $\mathrm{Mr}$. Rider to inform us that we have been on the wrong track all the time. A fundamental weakness of virtually every scheme for library cooperation, he believes, is scholars' insistence on having their research materials immediately at hand rather than in some other library. The point is, of course, not new. Librarians have long had to reckon with this attitude on the part of scholars, acknowledging it as a major obstacle in the way of coordination of library resources. At the same time, it has been realized that it is impossible for even the largest libraries, as they are now organized, to possess more than a fraction of existing literature. The microprint collections proposed by Mr. Rider would, if capable of actual realization, achieve a double purpose: give the scholars all they have been asking for these many years and save libraries from being buried under mountains of print-a utopia indeed!

Assuming the consummation of such a program as Mr. Rider advocates, library cooperation will still be essential. Subject specialization, for example, will be required on the part of libraries undertaking to issue microprint cards, in order to avoid duplication in publishing; agreements will be needed to insure more thorough coverage than at 
present of the world's literature; and more complete union catalogs will be wanted. The labors of proponents of library cooperation will, therefore, not have been in vain.

It is an intriguing prospect that $\mathrm{Mr}$. Rider opens up to us and one with almost unlimited potentialities. The usefulness of the microprint technique is obvious for dissertations, government publications, newspapers, and other space-consuming but infrequently used categories. It may be equally valuable for analytical cataloging, particularly periodical articles, festschrift contributions, and society proceedings, now so frequently buried, except for the most persistent investigator. The chief application of microprint, as these comments would indicate, is clearly to research materials.

The technical and administrative problems raised by the Rider plan are numerous and complex, as is inevitable with any radical transformation. Among the' snags might be mentioned the quantity and quality of projectors required, the fact that original copies must precede photographic reproductions, and scholars' frequent refusal to accept reproductions in lieu of originals. Granting that these and similar dilemmas can be successfully resolved, we have in microprint a tool that may well lead to tremendous expansion of facilities for advanced study, distributed in all regions of the country, making accessible resources previously available only in the largest library centers.-Robert B. Downs, director, University of Illinois Library and Library School.

Mr. Rider's proposal for the transfer of books to micro-cards is a genuinely epochal idea. If widely adopted, it would mark the first significant change in books since the substitution of the codex for the roll. No one has really been satisfied with microfilm as a vehicle for print, even with the benefit of a good reading machine. Sixteen millimeter film in short strips, or two hundred-foot reels, is a troublesome, ungainly vehicle for print. Coupled with the inconvenience inherent in any reading machine-other than one that would be no more inconvenient than bifocal spectacles-film is at best a surrogate for the book itself. Microfilm, after all, is simply a brillant adaptation of a material designed for another purpose-the motion picture.
Mr. Rider's proposal to put a micro-image of the book on paper and to limit the size of that paper to the standard catalog card, takes advantage of important conventionalities of book users and librarians; both are persuasive arguments for his scheme.

It is easy to see objections and difficulties in this proposal. Like all general departures from custom, the micro-card will be met, not only by the active objection of the conservative, but also by a more delaying general inertia. The greatest problem is to get the practice started; yet to commence, someone must undertake a great deal of fresh work in creating a manufacturing plant-simple though it may be-in surmounting copyright hurdles, and in setting up a distribution mechanism. It is to be hoped that the Readex Corporation will seize on the micro-card as pertinent to its procedures and offer books in micro-card form. Great impetus to the idea could be given by one or two libraries if they would substitute a few micro-card editions of scarce and sought-after works for microfilm editions. Once the form exists in a sufficient number of titles, librarians will accept it and absorb it into their economy.

A force working against easy, widespread acceptance is the problem of the reading machine, to which scholars are not yet accustomed. Man for centuries has read with nothing but the unaided eye, or at least with nothing more than the aid of that private magnifier, the eye glass. To persuade him to augment his simple vision with a more elaborate and ponderous device will require much time and much ingenuity on the part of inventors and manufacturers of such devices. As with microfilm, general acceptance of the micro-card may have to wait on the development of light, compact, and inexpensive reading apparatus.

To the librarian, however, the micro-card offers no greater problems than confront him daily and would confer, if generally available, so many advantages as to yield a substantial bibliothecal profit.-Donald Coney, librarian, University of Texas.

Most of the thinking that has been done on the problem of library cooperation-both in the realms of collecting and processes-has been based on a philosophy of scarcity of library materials. The assumption is that 
since not all libraries can afford to buy or maintain complete research collections in all fields, it follows that there should be some division of effort both in collecting and processing. As long as it is left in general terms, the argument sounds logical, but when put in specific situations and when carried to its ultimate conclusion, it raises more questions than it settles and puts the library in the position of being the tail that wags the dog.

But there is no reason why our thinking should be limited to a philosophy of scarcity. Once you express the possibilities in terms of a philosophy of abundance of library materials, you open up lanes of thought that appear to be harmonious with what all of us know to be the needs of the serious and professional scholar. Specifically, the philosophy of scarcity and specialization runs counter to the fact that, although a scholar always specializes, his library needs can seldom be limited to any one subject field. Nor is it easy to visualize our scholars (like a hive of busy bees passing from rose to snapdragon gathering up pollen on the way) voyaging from one institution to another in order to find and use our library materials.

Rider's primary contribution, therefore, is that he has made it possible for us to think in terms of a philosophy of abundance of ma- terials. His second contribution is that he has shown us one good way of throwing off the yoke of technical processes. His third contribution is that he holds out the vision of librarianship on a high level of scholarship, and by so doing will probably scare the wits out of the profession.

Rider is merely standing at the head of a long line of people who have realized that modern technology must be reckoned with.

In discussing his plans, I seriously hope that we will be careful to keep first things first. Will this plan permit the scholar access to his tools in a form that he will use? I am guessing that it would if we librarians have sufficient vision and wisdom. What about the roI complicating details? If the answer to the first question is yes, these can and will be met in due time. But if we start out by discussing details first, we will most certainly never get to the important question.

Here is a great opportunity that we librarians cannot afford to muff, but muff it we will if we take the attitude of "let George do it." Let's put aside our knitting in the A.C.R.L. and the A.R.L. and put our talents to work on something really important.Ralph Eugene Ellsworth, director of libraries, State University of Iowa, Iowa City.

\section{Author's Statement: Fremont Rider}

When Mr. Metcalf, with his customary courtesy, sent me an advance copy of his review, he termed it, in an accompanying letter, a "critical" one; but it is really so generous that I am "replying" to it only because I feel that some of his criticisms-entirely unintentionally of course-do not quite correctly present my position on some of the points I tried to bring out in my book.

A good example is his entirely proper reproof of that overoptimism that anticipates an extreme reduction in microprint as an immediate practical possibility. Many readers of the book have been so dazzled by the reductions that I refer to as probably ultimately practicable, that they overlook my categorical statement that, for micro-cards, such ultimate reductions are neither necessary nor even desirable. I said:

If research materials can be said to have any common denominator, it is the fact that, on the whole, they come in small packages-in periodical articles, pamphlets, government documents, committee reports, society proceedings, and the like. As has been already pointed out, it is the secondary material, the re-serving up of primary fact for the general reader, that usually blossoms out into full-length book form.

It is largely because research material comes in small packages, and is, as a result, minutely specialized, that it tends to be hard to get at. But the very reasons that have tended to bury it, bibliographically speaking, are exactly the reasons that make it fit so admirably into the micro-card set-up. The area of a single catalog card is, after all, a limited one. Although, under compression, it will take longer items, it is best suited to items not over, perhaps, a hundred pages long. But for research material this length is almost ideal. Probably 95 per cent of all its separable "units"-all of its many millions of books, proceedings, periodical 
articles, reports, theses and pamphlets-run to less than one hundred pages. Probably the average size of a unit of research material would not be over sixty or seventy pages. In other words, micro-cards on the one hand, and research materials on the other, seem naturally to "match up." And, when we do come to the occasional research item that runs to over two hundred pages, we can either arbitrarily split it up for separate micro-card "analysis," if it appears to split along well definable subject lines, or we can, as has already been suggested, take recourse to a continuing series of two or more micro-cards.

The micro-card sample reproduced as the frontispiece of the book can be read by the Readex reading machine just as well as by microscope, and no one yet who has examined it doubts that micro-cards having between fifty and one hundred pages of text on their backs are, as I state in the above quotation, entirely practicable now. During the past three months I have been in repeated conferences with the technological experts of two of our largest photographic equipment corporations; they all take the attitude that, in discussing future reduction possibilities, my book is quite unduly conservative. But even if one discounts their enthusiasm 60 or 70 per cent, we still will be where we started: that what I termed an "average length" micro-card is entirely practicable now. I stated explicitly, by the way (p. 107), that the frontispiece sample was made photographically; whether so great a reduction in the making of a print is practicable by the Readex process I am not enough familiar with its technology to know. But, so far as reading goes, the Readex machine, although it obviously is subject to improvement, performs now with reasonable effectiveness not only on this but on even greater reductions.

Mr. Metcalf emphasizes his belief that our great libraries are not going to continue indefinitely to grow at the doubling-every-sixteenyears rate. But on this point we have no disagreement. In my book, after summarizing the arguments pro and con, I also stated categorically (p. I6) that I thought they would not. But I would add-and this seems to me the vitally significant point-that, even though their rate of increase should shrink to doubling-every-twenty-years-or every thirty, or every forty years - the growth figures would still be so "astronomical" that the practical problems posed by them would be staggering ones.

If libraries continue to grow at present rates, if they continue to collect omnivorously, and if micro-card analytics should swell our present form of catalog fortyfold (as Mr. Metcalf suggests) - and not one of these "ifs" seems to me valid-then it may very well be true (as he estimates) that Yale's micro-card library of the year 2040 would occupy half a square mile of floor space. But the essential point to remember is that, if we assume all these same "ifs," but assume, instead of microcards, the same material retained in its original book form, then we would still have the same half square mile of catalog but, with it, we would have a book library occupying (by a very rough estimate indeed) some twelve square miles of floor space!

Furthermore, we must always remember that the making of analytics is in no sense an essential feature of the micro-card plan; I mentioned it as simply one of several possible modifications of our present procedure that it would permit if we desired to have it do so. And I had never had any thought myself that analytics, if they were made at all, would be made in any such a flood as Mr. Metcalf proposes. Only a minority of volumes would, as I see it, require analytics at all; and only a small percentage of those that required them would need as many as a dozen. Also it must be remembered that I proposed an offset to them in the form of an omission of some of our relatively less valuable series, translator, illustrator, and other present added entries. In other words, instead of our suggested analytics increasing the volume of our microcard library fortyfold I saw rather an analytics file perhaps tripling or quadrupling the present card catalog in size.

\section{Price of the Cards}

Mr. Metcalf questions the "round" price of five cents a card for micro-cards which the book-though explicitly it does so very tentatively indeed-sets. The book's discussion of micro-card prices is scattered in several places, and I find is neither a comprehensive nor as consistent as it should have been. It will be recalled, however, that it suggested that "first" cards should cost more than second and succeeding ones and that cards sold individually (if they are to be so sold) would 
properly cost more than "global" ones. Also cards bearing an author's royalty (if there are to be any such) would have added to them the cost of this royalty. It is conceivable that some cards might bear all three additions to "basic" cost. I am very far from asserting, however, that five cents will surely be enough even for basic cards; too many cost factors are still obscure. But, even if micro-cards cost six or seven cents each (or ten cents for that matter), our fundamental thesis is obviously not materially affected. And I still am inclined to think that, for cards issued in adequately large editions, a basic sales price of five cents a card will prove to be enough.

\section{Subject Heading Proposals}

On the other hand, I frankly admit that in attacking my subject heading proposals $\mathrm{Mr}$. Metcalf attacks my book at its most vulnerable point. As my whole chapter on microcard headings implies and as, indeed, I clearly stated (p. 148), I was by no means clear in my own mind as to the method by which the subject approach to micro-card materials ought to be arrived at. I fully agree with Mr. Metcalf that the research worker makes relatively little use of dictionary-catalog subject headings but the reason for this-as the chapter cited itself says-is that our present dictionary-catalog subject headings are, for him, inadequate. He most frequently uses a subject approach to his materials, to be sure, but it is a subject approach gained via abstracts, indexes, bibliographies, or other tools rather than via the dictionary catalog. I am glad to be able to state that a much more nearly satisfactory solution of this subject-heading problem is now in process of being arrived at. This solution was suggested to me by members of the cataloging division of the Library of Congress, at a series of conferences which I held with them two months ago on various practical details of the micro-card plan. There remain one or two minor questions relative to this solution still to be settled, but it is, I think, permissible to say here that this new plan will offer an entirely new kind of subject approach to cataloged materials, that it supersedes a large part of what was said on this subject in my book, and that it will, I believe, pretty well meet Mr. Metcalf's wellreasoned and cogent criticisms on this point.
Of course I entirely concur in his advocacy of "division of fields." Indeed, my book refers to such a division of fields as an almost essential part of any plan for micro-card publication.

\section{Original vs. Micro-Reduction}

Finally, he suggests that we are disagreed on another point, on which a careful rereading of my text will show that we probably are in entire accord. I fully agree that the research worker will generally prefer an original text to any micro-reduction of it. What I insist is that he will always prefer a micro-text, poor and difficult to use though that micro-text may be, to no text at all. And I further insist that, even if the original text can be secured from California-or elsewhere -on interlibrary loan, he will still be glad to have a micro-text of it at his elbow: a. to see if he really needs to borrow the original text; b. to use in place of the original text for purely casual reference; c. to use while he is waiting to get the original text on interlibrary loan; d. to have blown up for him photostatically if he feels he must have substantially the equivalent of the original text and must have that equivalent immediately.

Mr. Fussler, in his review, clearly and concisely puts his finger on some of the most vital practical difficulties which micro-cards face, and Dr. Bennett, equally clearly, emphasizes the necessity of micro-card standardization. She probably is correct also in stating that there is almost everywhere a need to educate library patrons in the use of micromaterials. I am inclined to think, however, that, if we give them convenient and desired materials-and good reading machines-they will very quickly educate themselves. The quotation which she specifically criticizes is -if I may venture to say so-not quite fair to the book, for she removes it from its concluding context. What I really said was, not "There is no particular point in suggesting that one is afraid that the patrons of one's library wouldn't like micro-texts of government documents," but that there is no particular point in a librarian's making this suggestion "when the original documents are simply not to be had" in any other form -obviously quite a different matter. If it is a case of micro-documents or no documents at all, the scholar must take the micro-docu- 
ments-whether he likes them or not. But this is very different from suggesting that I would discourage micro-education as a general proposition.

Dr. Bennett is also completely right in asserting that one single micro-reader must cover the entire reduction range that we propose using. She may not be aware, however, how great that range is. We by no means have to reduce our material to the same page size, or anything like it; quite the contrary. We should, for our micro-cards, reduce it to its most readable type-size within the over-all area that we decide that we have available for it and we must do this quite regardless of page sizes. It is true, of course, that if we desire to put only ten pages on our micro-card, the type-size we reduce to may very well be considerably larger than if we want to put fifty pages on the card. But, even so, one single reading machine would handle the resulting variation in type-size without any difficulty. On the other hand, I would not advise swelling up a single page to cover the entire back of a micro-card just because it happened that one page was all we wanted to put on that card. The resulting enlarged image could be read but it would be grotesquely, and quite unnecessarily, large. ${ }^{1}$

Mr. Moriarty is, of course, quite right in suggesting that micro-cards will have a large place in the music field. Among the microcard samples which we made were a number of interesting experiments in music scores in micro-card form. We even played with the idea of micro-reading machines built into organs, pianos, and the like, and of special reading machines on easels for orchestra use. This matter of micro-card music was simply

1 Unless, perhaps, it were so large on the micro-card that it could be read with the naked eye! one of the numerous extensions of the microcard idea which I omitted from the book, not because they had no merit, but because it was getting too long.

Mr. Montignani is the first, I think, ever to term me "ultra-conservative!" $\mathrm{He}$ accuses me of "penny-pinching." Now saving a few pennies on a single card may indeed seem to be penny-pinching, but, when those few pennies are multiplied by many billions of cards, they become pennies that have acquired not merely financial and bibliographical, but educational and even social, significance.

Mr. Downs's insistence that interlibrary cooperation is an essential prerequisite of any sound micro-card development, of course, reiterates something that simply cannot be reiterated too often. Mr. Freehafer properly points out a number of the "service" difficulties that are bound to develop if and when micro-cards come into anything like general use-and, equally properly, admits that these difficulties must, and can, be solved when the time comes. And Mr. Coney very properly stresses our great need for a better microprint reading machine-and one definitely adapted to micro-card use.

Dr. Ellsworth's warning that it is welibrarians-who must do the work of making micro-cards a realized tool is timely. There is a lot of it to be done. Micro-cards are now only a challenge, an opportunity. I am glad to report that the micro-card committee which the book suggests is already in process of appointment. May I earnestly bespeak for it here the active aid, the clarifying advice, the constructive criticism of every librarian; it is surely going to need all of these things that it can get.-Fremont Rider, librarian, Wesleyan University, Middletown, Conn. 